\title{
Sulfur globule oxidation in green sulfur bacteria is dependent on the dissimilatory sulfite reductase system
}

\author{
Carina Holkenbrink, Santiago Ocón Barbas, Anders Mellerup, \\ Hiroyo Otakit and Niels-Ulrik Frigaard
}

Correspondence

Niels-Ulrik Frigaard

E-mail: nuf@bio.ku.dk

Received 17 August 2010

Revised 28 November 2010

Accepted 7 January 2011
Department of Biology, University of Copenhagen, Ole Maaløes Vej 5, 2200 Copenhagen N, Denmark

Green sulfur bacteria (GSB) oxidize sulfide and thiosulfate to sulfate, with extracellular globules of elemental sulfur as an intermediate. Here we investigated which genes are involved in the formation and consumption of these sulfur globules in the green sulfur bacterium Chlorobaculum tepidum. We show that sulfur globule oxidation is strictly dependent on the dissimilatory sulfite reductase (DSR) system. Deletion of $d s r M / C T 2244$ or $d s r T / C T 2245$, or the two dsrCABL clusters (CT0851-CT0854, CT2247-2250), abolished sulfur globule oxidation and prevented formation of sulfate from sulfide, whereas deletion of $d s r U / C T 2246$ had no effect. The DSR system also seems to be involved in the formation of thiosulfate, because thiosulfate was released from wild-type cells during sulfide oxidation, but not from the $d s r$ mutants. The $d s r$ mutants incapable of complete substrate oxidation oxidized sulfide and thiosulfate about twice as fast as the wild-type, while having only slightly lower growth rates (70-80\% of wild-type). The increased oxidation rates seem to compensate for the incomplete substrate oxidation to satisfy the requirement for reducing equivalents during growth. A mutant in which two sulfide : quinone oxidoreductases (sqrD/CT0117 and sqrF/CT1087) were deleted exhibited a decreased sulfide oxidation rate ( $~ 50 \%$ of wild-type), yet formation and consumption of sulfur globules were not affected. The observation that mutants lacking the DSR system maintain efficient growth suggests that the DSR system is dispensable in environments with sufficiently high sulfide concentrations. Thus, the DSR system in GSB may have been acquired by horizontal gene transfer as a response to a need for enhanced substrate utilization in sulfide-limiting habitats.

\section{INTRODUCTION}

Phototrophic sulfur bacteria oxidize inorganic sulfur compounds (in particular sulfide, thiosulfate and elemental sulfur) for photosynthetic growth (Brune, 1989; Frigaard \& Dahl, 2009; Overmann, 2008). They thrive in anoxic marine and freshwater environments, where sulfide and light occur together. These bacteria are divided into the green sulfur bacteria (GSB; phylum Chlorobi, family Chlorobiaceae) and the purple sulfur bacteria (PSB; class Gammaproteobacteria, families Chromatiaceae and Ectothiorhodospiraceae) (Imhoff, 2008). Although these two major groups share certain ecological functions, their overall physiology and evolutionary origins are very

†Present address: Department of Biological Sciences, Graduate School of Science, Tokyo Metropolitan University, Minami-ohsawa 1-1, Hachioji 192-0397, Japan.

Abbreviations: APS, adenylye sulfate (adenosine 5'-phosphosulfate); DSR, dissimilatory sulfite reductase; GSB, green sulfur bacteria; PSB, purple sulfur bacteria; Sat, sulfate adenylyltransferase; SOX system, sulfur-oxidizing system; SOR, sulfide : quinone oxidoreductase.

Three supplementary figures and two supplementary tables are available with the online version of this paper. different. Despite these differences, GSB, PSB and certain chemotrophic prokaryotes (including sulfate reducers, and sulfide- and thiosulfate-oxidizing chemolithotrophs) metabolize inorganic sulfur compounds using homologous enzyme systems that have been exchanged by horizontal gene transfer (e.g. Klein et al., 2001; Meyer et al., 2007). The sulfur metabolism of GSB and PSB has been studied for decades (Brune, 1989; Frigaard \& Dahl, 2009; Sakurai et al., 2010). Nevertheless, a solid understanding of the pathways and mechanisms of the oxidation of sulfide, sulfur globules and thiosulfate has still not been achieved.

Genome sequencing has greatly increased our understanding of the sulfur metabolism in GSB (Chan et al., 2008a; Frigaard \& Bryant, 2008), and their physiology and evolution in general (Eisen et al., 2002; Frigaard et al., 2003). Chlorobaculum tepidum TLS was the first green sulfur bacterium for which genome sequence information was made available (Eisen et al., 2002). This strain grows rapidly on sulfide and thiosulfate, and has been used extensively as a model organism for genetic and physiological studies. A model of the dissimilatory sulfur metabolism in C. tepidum based on recent studies is shown in Fig. 1. 


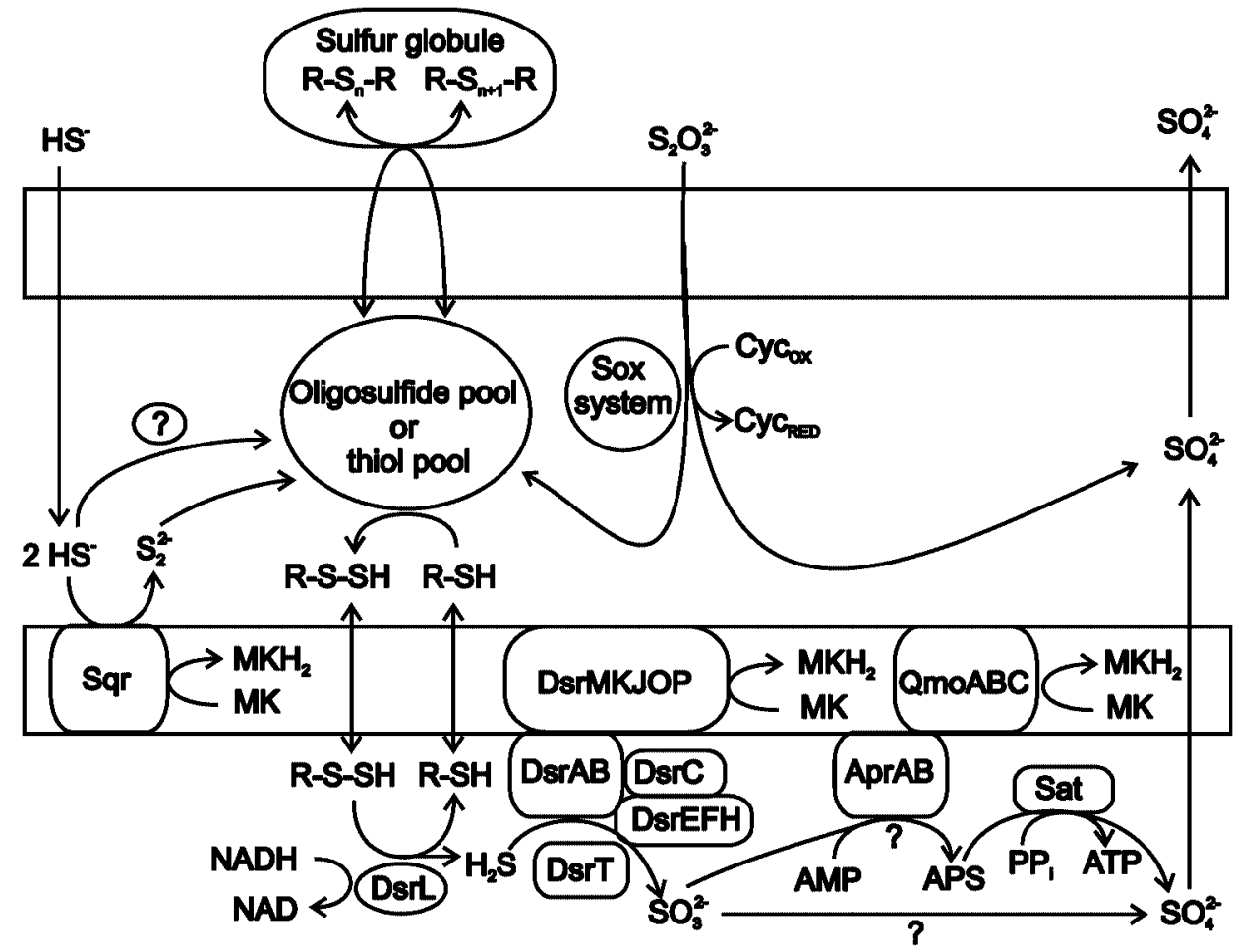

Fig. 1. Overview of proposed pathways of the thiotrophic sulfur metabolism of C. tepidum (Eisen et al., 2002; Frigaard \& Bryant, 2008; Sakurai et al., 2010). Abbreviations: APS, adenosine 5'-phosphosulfate; MK, menaquinone; Sat, sulfate adenylyltransferase.

Both GSB and PSB form sulfur globules by incomplete oxidation of sulfide (Frigaard \& Dahl, 2009). The exact molecular structure of this sulfur (often referred to as 'elemental sulfur') is still debated, but it is thought to occur as long-chain, zero-valent polysulfanes, probably terminated by organic residues (Prange et al., 2002). In most PSB, such as Allochromatium vinosum, the sulfur globules are deposited in the periplasmic space of the cells and are encapsulated by proteins, whereas the sulfur globules of GSB are deposited extracellularly and are not known to be associated with protein. When reducing equivalents are needed (e.g. if sulfide is depleted), the sulfur globules are oxidized completely to sulfate.

The mechanisms involved in the formation and consumption of sulfur globules in PSB and GSB are largely unknown (Frigaard \& Dahl, 2009). It has been proposed that a periplasmic pool of oligosulfides or organic thiols serves as an intermediate between sulfur in the globules and the enzymes that oxidize sulfur compounds in the cell (Fig. 1). The only genes known to be essential for oxidation of sulfur globules in PSB are the $d s r$ genes, which in $A$. vinosum are located in a single cluster, dsrABEFHCMKLJOPNRS (Dahl et al., 2005). These genes encode a dissimilatory sulfite reductase (DSR) system that is homologous to that in sulfatereducing bacteria but operates in the reverse (oxidative) direction. The Dsr proteins that appear to be common among all DSR-containing bacteria are a sirohaem- or siroamide-containing sulfite reductase (DrAB), a transmembrane electron-transporting complex (DsrMKJOP), a putative sirohaem amidase (DsrN), and the DsrC protein. In addition, A. vinosum and other sulfide oxidizers (e.g. GSB, Thiobacillus denitrificans, Magnetococcus sp. MC-1) contain a putative sulfur transferase complex (DsrEFH) and an ironsulfur flavoprotein with $\mathrm{NADH}$ oxidoreductase activity (DsrL). Individual gene inactivation of $d s r A, d s r B, d s r H$, $d s r M, d s r K, d s r L, d s r J, d s r O$ and $d s r P$ completely prevents oxidation of sulfur globules in A. vinosum, whereas individual gene inactivation of $d s r N$ and $d s r R$ significantly reduces the oxidation rate of sulfur globules (Dahl et al., 2005; Grimm et al., 2010; Lübbe et al., 2006; Pott \& Dahl, 1998; Sander et al., 2006).

All GSB capable of growth on sulfur compounds (other than Chloroherpeton thalassium) contain $d s r$ genes (Frigaard \& Bryant, 2008). In C. tepidum, the genes are split into two clusters, dsrNCABL6TMKJOP89 (CT2251-2238) and dsrCABLEFH (CT0851-0857), such that $d s r C A B L$ is duplicated. The published genome sequence of $C$. tepidum contains a frameshift mutation in $d s r B 2 / C T 2248$, providing a possible explanation for the duplication (Eisen et al., 2002). In Chlorobium and Prosthecochloris strains, all $d s r$ genes are organized in a single cluster. Although the DSR system appears to be similar in A. vinosum and GSB, there are some notable differences in the components and their evolutionary origin. The $d s r$ genes in C. tepidum include CT2238, 
Table 1. Strains of C. tepidum used in this study

\begin{tabular}{|c|c|}
\hline Strain & Genotype \\
\hline $\mathrm{CH} 1$ & Wild-type (derived from strain TLS) \\
\hline$s q r D$ & $\Delta \mathrm{CT} 0117::$ aadA $\left(\mathrm{Sp}^{\mathrm{R}}\right.$ marker from pSRA81) \\
\hline$s q r F$ & $\begin{array}{l}\Delta \mathrm{CT} 1087: \text { : cat-erm } C\left(\mathrm{Cm}^{\mathrm{R}}-\mathrm{Em}^{\mathrm{R}} \text { marker }\right. \\
\text { from pJHJ06) }\end{array}$ \\
\hline$s q r D s q r F$ & $\Delta$ CT0117::aadA $\Delta$ CT1087: : cat-ermC \\
\hline$d s r U$ & $\Delta \mathrm{CT} 2246::$ aadA $\left(\mathrm{Sp}^{\mathrm{R}}\right.$ marker from $\left.\mathrm{pJHJ} 02\right)$ \\
\hline$d s r T$ & $\Delta \mathrm{CT} 2245::$ aadA $\left(\mathrm{Sp}^{\mathrm{R}}\right.$ marker from $\left.\mathrm{pJHJ} 02\right)$ \\
\hline$d s r M$ & $\Delta \mathrm{CT} 2244::$ aadA $\left(\mathrm{Sp}^{\mathrm{R}}\right.$ marker from pSRA81) \\
\hline dsrCABL1 & $\begin{array}{l}\Delta(\mathrm{CT} 0851-\mathrm{CT} 0854):: \text { aadA }\left(\mathrm{Sp}^{\mathrm{R}} \text { marker }\right. \\
\text { from pSRA81) }\end{array}$ \\
\hline dsrCABL2 & $\begin{array}{l}\Delta(\mathrm{CT} 2247-\mathrm{CT} 2250):: \text { cat-erm } C\left(\mathrm{Cm}^{\mathrm{R}}-\mathrm{Em}^{\mathrm{R}}\right. \\
\text { marker from pJHJ06) }\end{array}$ \\
\hline dsrCABL $1 / 2$ & $\begin{array}{l}\Delta(\mathrm{CT} 0851-\mathrm{CT} 0854):: \text { aadA } \Delta(\mathrm{CT} 2247- \\
\text { CT2250): : cat-erm } \mathrm{C}\end{array}$ \\
\hline $\begin{array}{l}\text { Complemented } \\
d s r M\end{array}$ & $\Delta \mathrm{CT} 2244::$ aadA $\Delta \mathrm{CT} 0028::(\mathrm{CT} 2244 \mathrm{ermC})$ \\
\hline
\end{tabular}

CT2239, dsrT/CT2245 and CT2246, which are not found in A. vinosum (Frigaard \& Dahl, 2009). The $d s r T$ gene is found only in GSB and sulfate reducers (Mussmann et al., 2005; Sander et al., 2006). Phylogenetic studies have shown that the DsrTMKJOP proteins in GSB are closely related to their homologues in sulfate-reducing bacteria, whereas most other Dsr proteins in GSB are closely related to their homologues in PSB (Sander et al., 2006). The dsrRS genes found in A. vinosum are not found in GSB.

Several enzymes have been proposed to oxidize sulfide in C. tepidum, including sulfide:quinone oxidoreductase (SQR) and flavocytochrome $c$ (Eisen et al., 2002). In C. tepidum, the membrane-bound SQR homologues CT0117 and CT1087 are responsible for some of the sulfide oxidation activity in the cells (Chan et al., 2009). Thiosulfate oxidation in GSB is carried out by the sulfuroxidizing (SOX) system in a manner similar to that in $A$. vinosum (Azai et al., 2009; Ogawa et al., 2008). In the proposed pathway the sulfone moiety of thiosulfate is oxidized to sulfate and released, whereas the sulfane moiety is released to the putative pool of sulfur globule precursors and subsequently either deposited in sulfur globules or oxidized to sulfite by the $d s r$ system (Fig. 1). Oxidation of sulfite to sulfate in C. tepidum has been proposed to be carried out by an APS reductase and a Sat (Eisen et al., 2002; Fig. 1).

In the present study we investigate the function and significance of several of the above-mentioned proteins with respect to sulfur metabolism and growth in C. tepidum, with a focus on formation and consumption of sulfur globules.

\section{METHODS}

Bacterial strains, media and growth conditions. All strains used in this study are listed in Table 1. Our wild-type strain (CH1) was derived from the plating strain of C. tepidum TLS (Wahlund et al., 1991), and was shown to have a restored reading frame of $d s r B 2 / C T 2248$. Unless otherwise stated, C. tepidum was grown in liquid CL medium or on solid $\mathrm{CP}$ plates (Frigaard et al., 2004) at $42{ }^{\circ} \mathrm{C}$ with an incandescent light intensity of $50 \mu \mathrm{mol}$ photons $\mathrm{m}^{-2} \mathrm{~s}^{-1}$. Cultivation, manipulation and sampling were performed in an anaerobic chamber with an atmosphere consisting of $5 \% \mathrm{H}_{2}, 10 \% \mathrm{CO}_{2}$ and $85 \% \mathrm{~N}_{2}$ (Coy Laboratory Products). Growth and oxidation rate experiments with various sulfur compounds were performed in sulfur-free CL3 medium supplemented with sterile, anoxic sulfide and thiosulfate stock solutions. One litre of CL3 medium contained $20 \mathrm{ml}$ of salts A3 (per litre: $0.64 \mathrm{~g}$ $\mathrm{Na}_{2}$ EDTA. $2 \mathrm{H}_{2} \mathrm{O}, 10 \mathrm{~g} \mathrm{MgCl} 2.6 \mathrm{H}_{2} \mathrm{O}, 2.5 \mathrm{~g} \mathrm{CaCl}_{2} .2 \mathrm{H}_{2} \mathrm{O}, 20 \mathrm{~g} \mathrm{NaCl}$ ), $20 \mathrm{ml}$ of salts B2 (per litre: $25 \mathrm{~g} \mathrm{NH}_{4} \mathrm{CH}_{3} \mathrm{COO}, 20 \mathrm{~g} \mathrm{NH}_{4} \mathrm{Cl}$ ), $20 \mathrm{ml}$ buffer (per litre: $25 \mathrm{~g} \mathrm{KH}_{2} \mathrm{PO}_{4}, 105 \mathrm{~g}$ MOPS), $1 \mathrm{ml}$ trace elements (Wahlund et al., 1991), $50 \mu \mathrm{l}$ resazurin $\left(10 \mathrm{mg} \mathrm{ml}^{-1}\right.$ ) and $20 \mu \mathrm{l}$ vitamin B12 $\left(1 \mathrm{mg} \mathrm{ml}^{-1}\right)$. After the solution had been autoclaved at $121{ }^{\circ} \mathrm{C}$ for $20 \mathrm{~min}$, the hot medium was cooled for $45 \mathrm{~min}$ while bubbling with $\mathrm{N}_{2}$ under sterile conditions. Inside the anaerobic chamber, $50 \mathrm{ml}$ sterile, anoxic $\mathrm{NaHCO}_{3}$ solution $(2 \mathrm{~g})$ and $1 \mathrm{ml}$ sterile, anoxic sodium ascorbate $(1 \mathrm{M})$ were added. The final $\mathrm{pH}$ of the medium was between 6.9 and 7.0. Prior to use, the medium was stored overnight in the anaerobic chamber until it became colourless. Cells of $C$. tepidum used for experiments with sulfur compound transformation were grown overnight (14-18 h) in CL medium and pelleted by centrifugation for $7 \mathrm{~min}$ at $720 \mathrm{~g}$ (outside the anaerobic chamber). The cell pellet was resuspended in CL3 (inside the anaerobic chamber) before sulfide or thiosulfate was added. Sulfur transformation measurements were performed in cultures $(16 \mathrm{ml})$ in screw-capped tubes placed in a rotating wheel at $42{ }^{\circ} \mathrm{C}$ inside the anaerobic chamber.

Quantification of sulfur compounds, protein and BChl c. For sulfide analysis, one volume of sample was fixed in 2.5 volumes of $2 \%$ $(\mathrm{w} / \mathrm{v})$ zinc acetate dihydrate (supplemented with $0.2 \%$, v/v, acetic acid). The sulfide concentrations were determined colorimetrically as described by Cline (1969). Each sulfide concentration in the study is the mean of technical duplicates. Elemental sulfur, BChl $c$ and protein were determined on the same sample of pelleted cells. Cell suspension $(0.2-$ $1.0 \mathrm{ml}$ ) was pelleted by centrifugation $(1 \mathrm{~min}, 5000 \mathrm{~g}$ ). To remove traces of ascorbate, the pellet was washed with $500 \mu \mathrm{l} \mathrm{Na} \mathrm{NPO}_{4} / \mathrm{NaH}_{2} \mathrm{PO}_{4}$ (20 mM, pH 7.0) and stored at $-80{ }^{\circ} \mathrm{C}$ until the measurements were performed. Elemental sulfur, $\mathrm{BChl} c$ and $\mathrm{BChl} d$ were extracted by resuspending the cell pellet in methanol, and the concentrations were determined spectrophotometrically in the supernatant at 265, 669 and $659 \mathrm{~nm}$, respectively, using absorption coefficients of $23.91 \mathrm{~g}^{-1} \mathrm{~cm}^{-1}$ (Stal et al., 1984), $86 \mathrm{lg}^{-1} \mathrm{~cm}^{-1}$ and $82.3 \mathrm{lg}^{-1} \mathrm{~cm}^{-1}$ (Stanier \& Smith, 1960). The $A_{265}$ was corrected for pigment contribution by subtracting $40 \%$ of the $A_{669}$ and $A_{659}$, respectively (this percentage was empirically determined with sulfur globule-free wild-type cells). For protein determination, the methanol-extracted pellet was resuspended in $50 \mu \mathrm{l}$ $\mathrm{NaOH}(0.5 \mathrm{mM})$, and the protein concentration was determined using a total protein assay kit (TP0300, Sigma) using BSA as standard. High concentrations of sulfur globules did not affect the protein determination. All protein concentrations are means of technical triplicates performed on the same culture. Sulfate $\left(t_{\mathrm{R}}=9.2 \mathrm{~min}\right)$ and thiosulfate $\left(t_{\mathrm{R}}=19.9 \mathrm{~min}\right)$ were quantified by HPLC using indirect UV detection (detection wavelength $310 \mathrm{~nm}$, reference wavelength $360 \mathrm{~nm}$ ) and isocratic elution at ambient temperature $\left(\sim 20^{\circ} \mathrm{C}\right)$. The analysis was performed on a model 1100 HPLC system (Agilent) using a PRP-X100 column (dimensions $150 \mathrm{~mm} \times 4.1 \mathrm{~mm}$, particle diameter $5 \mu \mathrm{m}$ ) (Hamilton) and a mobile phase consisting of p-hydroxybenzoic acid (4 mM, pH 8.9) and methanol ( $2.5 \%, \mathrm{v} / \mathrm{v})$ in water. To avoid distortion of the sulfate concentration by sulfide oxidation, nine volumes of the sample were mixed with one volume $\mathrm{ZnCl}_{2}(100 \mathrm{mM})$ inside the anaerobic chamber and centrifuged prior to HPLC analysis.

Amplification and sequencing of the dsrB genes. To determine the sequence of $d s r B 1$ and $d s r B 2$, PCR amplicons were prepared using primer pairs $179 / 180$ and $268 / 271$, respectively, since these primers 
bind outside the homologous $d s r C A B L$ regions (Fig. 2a). The specific amplification of each locus was confirmed by sequencing the PCR amplicons using primer 260 (identical to primer CT2245U1; see Supplementary Table S1), since the sequencing reaction extends into the non-homologous region (Fig. 2a). Sequencing of the $d s r B$ genes in PCR amplicons obtained in separate experiments with the wild-type $(n=3)$ and the dsrCABL1 mutant $(n=5)$ was performed using primer 190 (5'-CATCAACCTACAGGAACGAG-3').

Mutagenesis of C. tepidum. Gene inactivation in C. tepidum was performed using natural transformation and homologous recombination, as previously described (Frigaard et al., 2004; Frigaard \& Bryant, 2001). Gene inactivation constructs were made either by an in vitro PCR-based 'ligation' approach or by a cloning-based approach (Frigaard et al., 2004; Jacobsen et al., 2011). Primers used for amplifying the homologous flanking regions of the target gene are listed in Supplementary Table S1, which also describes the mutagenesis strategy used for each mutant.

Plasmids for genetic complementation of the $d s r M$ mutant of $C$. tepidum were constructed using the $b c h U$ gene as expression platform, similar to the manner described by Maresca et al. (2008). Two homologous regions (A and B) flanking the start codon of the $C$. tepidum bchU gene were amplified by PCR using primers 486 and 487 for region A (865 bp), and primers 488 and 489 for region B (864 bp) (Supplementary Table S2). The amplified regions were fused by a second round of PCR using primers 486 and 489 and a 1:1 mixture of PCR products A and B as template. The $1753 \mathrm{bp}$ PCR product was cloned into pUC19 using EcoRI and HindIII, resulting in plasmid pCX. Plasmid pCX was engineered such that the start codon region contained an $\mathrm{NcoI}$ site and a multiple cloning site. The erm C cassette encoding erythromycin resistance was amplified with primers 500 and 501 and inserted into pCX using PstI and BamHI, resulting in plasmid pCX-Em. The $d s r M$ gene was amplified from genomic DNA using primers 496 and 510 and inserted into pCX-Em using NcoI and SpeI, resulting in the plasmid used for complementation of the $d s r M$ mutant. A map of the expression construct is shown in Fig. 2(b). Primers are listed in Supplementary Table S2. Correct insertion of the expression construct in the bchU locus was verified by PCR (primers 490 and 491) and the production of $\mathrm{BChl} d$ by the complemented $d s r M$ mutant.

Sulfur globule purification. Sulfur globules excreted by the dsrCABL1/2 mutant of C. tepidum were purified and used as growth substrates for other cultures. Overnight cultures of this mutant grown in CL medium were harvested by centrifugation (10 $\mathrm{min}, 4200 \mathrm{~g}$ ). The pellet was resuspended in buffer $\left(20 \mathrm{mM} \mathrm{Na} 2 \mathrm{HPO}_{4} / \mathrm{NaH}_{2} \mathrm{PO}_{4}\right.$, $\mathrm{pH} 7.0)$ containing sucrose $(50 \%, \mathrm{w} / \mathrm{v})$ and centrifuged $(5 \mathrm{~min}$, $3000 \mathrm{~g}$ ). The pelleted sulfur globules were washed once with buffer (20 mM Na $\mathrm{HPO}_{4} / \mathrm{NaH}_{2} \mathrm{PO}_{4}, \mathrm{pH} 7.0$ ) and resuspended in CL3 medium. For experiments with sulfur globule utilization, the stock suspension of sulfur globules was added to CL3 medium, which was supplemented with $0.1 \mathrm{mM}$ sulfide.

\section{RESULTS}

\section{Nomenclature of dsr and sqr genes in GSB}

CT2246 in C. tepidum encodes a $14 \mathrm{kDa}$ protein with no identified conserved sequence motifs. This gene is conserved in all $d s r$ gene clusters in GSB and we suggest naming this gene $d s r U$. Other than GSB, $d s r U$ (Mmc1_2160) is found only in the sulfide-oxidizing proteobacterium Magnetococcus sp. MC-1 (Schübbe et al., 2009) as part of the cluster dsrABLU (Mmc1_2156-2160).

CT2239 and CT2238 are also putative components of the DSR system because they are conserved in all $d s r$ clusters in GSB, and because they encode homologues of proteins that are specific to sirohaem biosynthesis (the cofactor of nitrite and sulfite reductases). We suggest naming these genes $d s r V$ and $d s r W$, respectively. Chlorobium ferrooxidans DSM 13031 contains distant homologues of $d s r V$ (ZP_01387072) and $d s r W$ (ZP_01387073), but these are part of the assimilatory sulfate reduction $c y s$ gene cluster (Frigaard \& Bryant, 2008).

CT0117 and CT1087 encode different SQR enzymes in C. tepidum (Chan et al., 2009). Phylogenetic analyses show that these SQRs and the SQRs from other organisms group in distinct clades (Chan et al., 2009; Frigaard \& Bryant, 2008; Theissen et al., 2003). We suggest naming CT0117

(a)
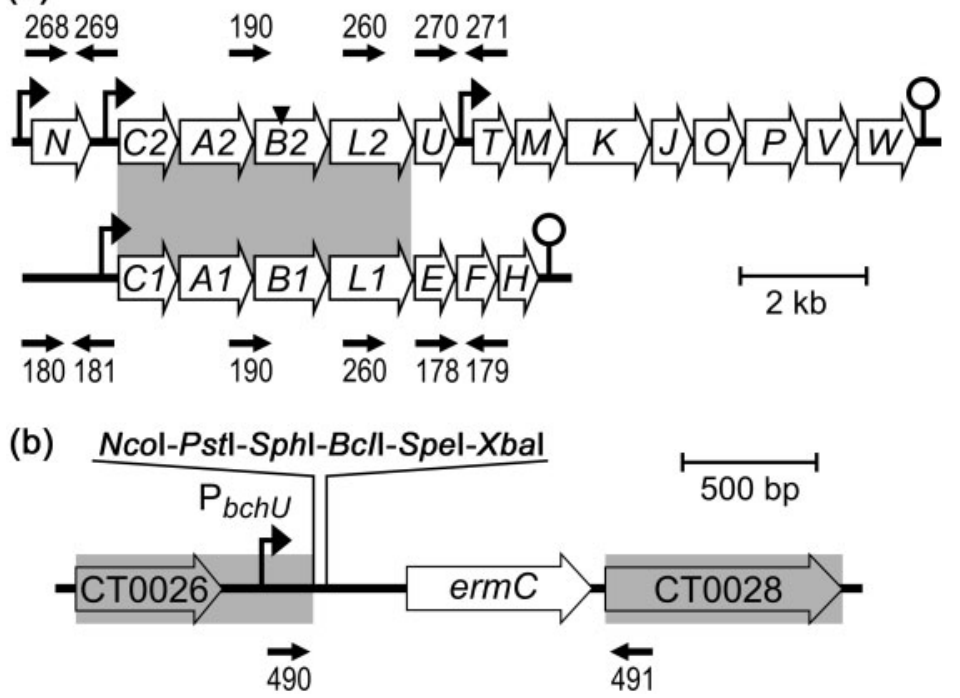

Fig. 2. (a) The $d s r$ gene clusters in C. tepidum (Eisen et al., 2002). Grey indicates regions of high sequence homology. The black triangle indicates the frameshift mutation in the published genome (Eisen et al., 2002). Black arrows indicate binding of primers for PCR and sequencing. Prediction of promoters and terminators was done using FGENESB software (http://linux 1. softberry.com/berry.phtml?topic= fgenesb\&group=programs\&subgroup=gfindb). (b) Map of the plasmid pCX-Em used for dsrM complementation in C. tepidum. Grey indicates regions homologous to the $C$. tepidum genome. The $d s r M$ gene was inserted in the $\mathrm{Ncol} / \mathrm{Spel}$ sites and is under the control of the bchU promoter $\left(\mathrm{P}_{b c h U}\right)$. 
Table 2. Genes related to sulfur metabolism and targeted for inactivation in C. tepidum

\begin{tabular}{|lcl|}
\hline Gene & Locus tag & \multicolumn{1}{c|}{ Putative function* } \\
\hline$s q r D$ & CT0117 & SQR, type SqrD \\
$d s r C 1$ & CT0851 & DSR system component, protein DsrC, copy 1 \\
$d s r A 1$ & CT0852 & DSR, subunit A, copy 1 \\
$d s r B 1$ & CT0853 & DSR, subunit B, copy 1 \\
$d s r L 1$ & CT0854 & DSR system component, protein DsrL, copy 1 \\
$s q r F$ & CT1087 & SQR, type SqrF \\
$d s r M$ & CT2244 & DSR system component, protein DsrM \\
$d s r T$ & CT2245 & DSR system component, protein DsrT \\
$d s r U$ & CT2246 & Putative DSR system component, protein \\
& & DsrU \\
$d s r L 2$ & CT2247 & DSR system component, protein DsrL, copy 2 \\
$d s r B 2$ & CT2248 & DSR, subunit B, copy 2 \\
$d s r A 2$ & CT2249 & DSR, subunit A, copy 2 \\
$d s r C 2$ & CT2250 & DSR system component, protein DsrC, copy 2 \\
& & \\
\hline
\end{tabular}

${ }^{\star}$ Chan et al. (2009), Eisen et al. (2002), Mussmann et al. (2005), Sander et al. (2006), this work.

and CT1087 as sqrD and $s q r F$, respectively, while reserving $s q r A, s q r B, s q r C$ and $s q r E$ for other groups of SQRs.

\section{Construction of knockout mutants}

Nine knockout strains of $C$. tepidum $\mathrm{CH} 1$ were constructed (Tables 1 and 2). The double mutant sqrD sqrF was made by transforming the $s q r D$ mutant with an $s q r F$ knockout construct. The double mutant dsrCABL1/2 was made by transforming the dsrCABL1 mutant with a dsrCABL2 knockout construct. Transformants segregated easily. The genotype of the mutants was confirmed by PCR amplification across the insertion site of the antibiotic-resistance cassette (Frigaard et al., 2004).

Individual inactivation of the $d s r A, d s r B, d s r C$ and $d s r L$ copies would require multiple cloning steps due to the duplication of the $d s r C A B L$ cluster (Fig. 2). Instead, mutants denoted dsrCABL1, dsrCABL2 and dsrCABL1/2 were constructed that lacked $d s r C 1 A 1 B 1 L 1, d s r C 2 A 2 B 2 L 2$ or both clusters, respectively. Mutant dsrCABL1 was made with a construct containing homologous regions made using primers 180, 181, 178 and 179 (Fig. 2). Mutant dsrCABL2 was made with a construct containing homologous regions made using primers $268,269,270$ and 271 (Fig. 2).

\section{dsrB gene sequences of C. tepidum}

According to the published genome sequence (NC 002932), C. tepidum TLS contains two copies of $d s r B$ ( $d s r B 1 / C T 0853$ and $d s r B 2 / C T 2248)$, in which $d s r B 2$ contains a frameshift mutation leading to a non-functional copy of $d s r B$ (Eisen et al., 2002). Sequencing of the $d s r B 2$ gene of the wild-type and the dsrCABL1 mutant revealed that $d s r B 2$ had reverted to a functional reading frame, such that the sequences of $d s r B 2$ and $d s r B 1$ were identical. Due to this genotype, which is different from the published genotype (Eisen et al., 2002), the C. tepidum wild-type strain used in this study is denoted $\mathrm{CH} 1$.

\section{Sulfide and thiosulfate utilization by wild-type and dsr mutants}

When sulfide was supplied to C. tepidum wild-type it was oxidized to sulfur globules, while a transient increase in thiosulfate could be detected (Fig. 3a, b). After sulfide depletion, the elemental sulfur and the thiosulfate formed were completely oxidized to sulfate. Thiosulfate supplied as sole sulfur source was likewise oxidized completely to sulfate, although no transient increase in elemental sulfur could be detected (Supplementary Fig. S1a). The dsrM mutant also oxidized sulfide but permanently accumulated elemental sulfur, and no increase in thiosulfate was observed (Fig. 3c, d). As in the wild-type, thiosulfate was oxidized in the $d s r M$ mutant upon depletion of sulfide. However, whereas thiosulfate was completely oxidized to a bimolar amount of sulfate in the wild-type, thiosulfate was oxidized to an equimolar amount of sulfate and elemental sulfur in the $d s r M$ mutant (Fig. 3 and Supplementary Fig. S3g; see also below). The dsrCABL1/2 mutant exhibited the same phenotype as the $d s r M$ mutant: sulfide was oxidized to an equimolar amount of elemental sulfur and no formation of sulfate or thiosulfate was observed (Supplementary Fig. S1b, c).

By optical microscopy, the accumulated extracellular sulfur in the $d s r M$ and dsrCABL1/2 mutants appeared as refractive globules similar to the sulfur globules formed by the wild-type, except that the sulfur globules from the $d s r$ mutants were larger (diameter $\sim 1-4 \mu \mathrm{m}$ ) than those from the wild-type (diameter $\sim 1 \mu \mathrm{m}$ ) (Supplementary Fig. S2). Sulfur globules produced by cultures of $d s r$ mutants also appeared to sediment faster. This behaviour probably contributed to the high SD values obtained in measurements of elemental sulfur concentration in suspensions containing these sulfur globules (e.g. Fig. 4).

Long-term incubations revealed a similar sulfur compound transformation pattern, as expected from the initial time-course experiment. C. tepidum wild-type oxidized $2 \mathrm{mM}$ sulfide completely within $24 \mathrm{~h}$ to $2 \mathrm{mM}$ sulfate, and $2 \mathrm{mM}$ thiosulfate to $4 \mathrm{mM}$ sulfate (Fig. $4 \mathrm{a}$ and Supplementary Fig. S3a). Mutant $d s r M$ oxidized sulfide to an approximately equimolar amount of elemental sulfur, while no increase in sulfate could be detected (Fig. 4g). The $d s r M$ mutant oxidized thiosulfate to an equimolar amount of sulfate and an approximately equimolar amount of elemental sulfur (Supplementary Fig. S3g). Mutants dsrCABL1/2 and $d s r T$ exhibited the same behaviour with respect to sulfide and thiosulfate oxidation, while mutant $d s r U$ behaved in a manner similar to that of the wild-type (Fig. 4 and Supplementary Fig. S3). 

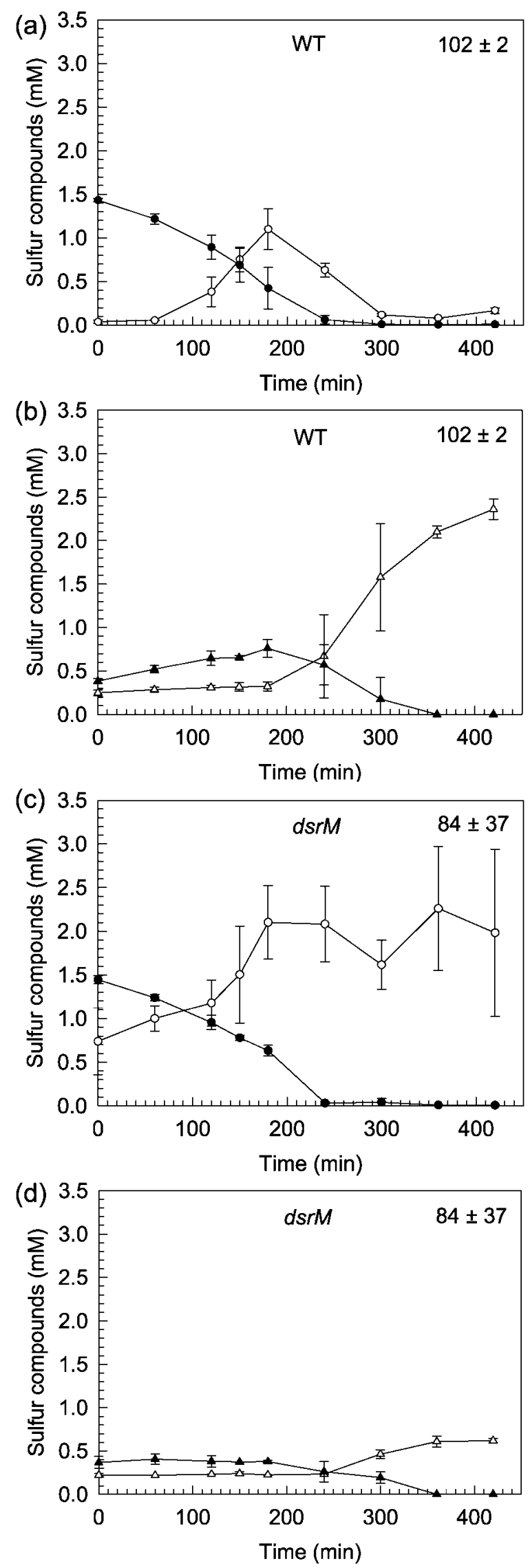

Fig. 3. Time-course experiments with the oxidation of sulfide (1.5 mM) in wild-type $(\mathrm{a}, \mathrm{b})$ and dsrM cultures $(\mathrm{c}, \mathrm{d})$ of $\mathrm{C}$. tepidum. The initial protein content of the cultures was $\sim 25 \mu \mathrm{g} \mathrm{ml}^{-1}$. Sulfide $(\bullet)$, sulfur $(\bigcirc)$, sulfate $(\triangle)$ and thiosulfate concentrations $(\boldsymbol{\Delta})$ were measured. The mean and standard deviation of replicate cultures $(n=2)$ are shown. The presence of thiosulfate $(0.4 \mathrm{mM})$ at time 0 is due to abiotic formation of thiosulfate during medium preparation. The sulfur recovery (of all sulfur compounds) at the end of the experiment expressed as a percentage of the initial sulfur concentration is shown in the upper-right corner.

These observations support the current model of sulfide and thiosulfate utilization in C. tepidum (Fig. 1), and show that sulfur globules are an intermediate component in both sulfide and thiosulfate oxidation. Furthermore, the observations suggest that both the sulfide and the thiosulfate sulfane sulfur enter the same pool of sulfur globule precursors.

Mutants lacking only one $d s r C A B L$ cluster (dsrCABL1 and dsrCABL2) both exhibited a strongly diminished ability to oxidize sulfur. Both mutants produced a small, yet statistically significant ( $t$ test, $P<0.05, n=3$ ) amount of sulfate upon oxidation of sulfide (Fig. 4c, d); however, even after $96 \mathrm{~h}$ of incubation sulfur globules were not oxidized (data not shown). These experiments show that oxidation to sulfate is completely abolished only in the double mutant and that both $d s r C A B L$ clusters are necessary for efficient oxidation to sulfate.

\section{Genetic complementation of the dsrM mutant}

The $d s r M$ mutant was complemented in trans with an expression construct of the $d s r M$ gene from the wild-type (see Methods). Long-term incubation showed that the complemented mutants regained their ability to produce sulfate from sulfide and thiosulfate, although the consumption rate of the sulfur globules was somewhat slower than in the wild-type and the bchU mutant (Fig. 4h and Supplementary Fig. S3h).

\section{Sulfur globule formation and consumption}

Sulfide oxidation results in the formation of oligosulfides, which are substrates for sulfur globule formation (Fig. 1). The SQR homologues in C. tepidum, SqrD and SqrF, have been shown to catalyse sulfide oxidation and are probably responsible for the formation of oligosulfides (Chan et al., 2009). However, time-course experiments in the present study showed that an $s q r D$ sqrF double mutant still produced sulfur globules as an intermediate when sulfide was oxidized (Supplementary Fig. S1d, e). This suggests that one or more additional unknown sulfide-oxidizing enzymes produces precursors of sulfur globule formation. Work is in progress to identify this enzyme activity. 

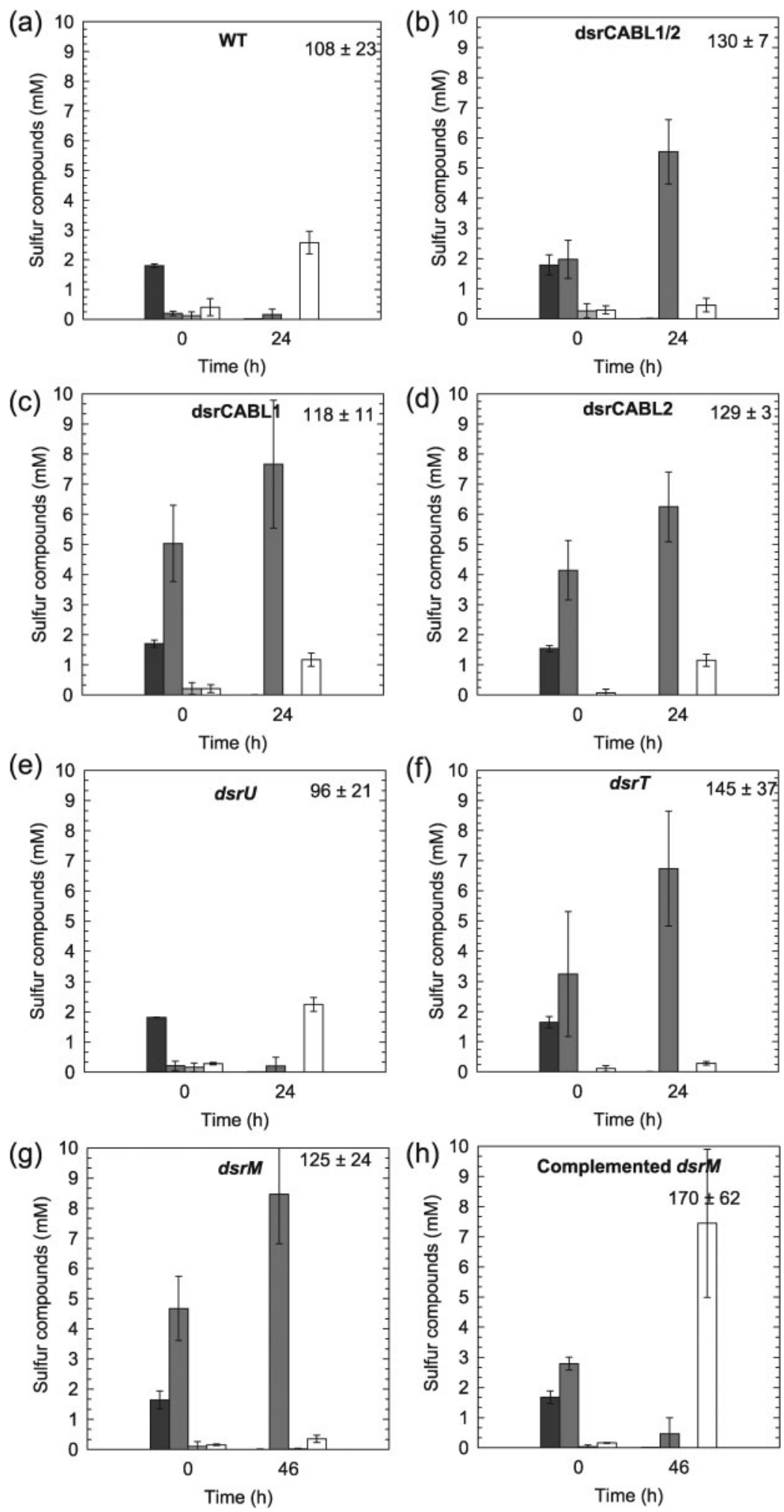

Fig. 4. Sulfide utilization ( $2 \mathrm{mM}$ ) by C. tepidum strains: (a) wild-type, (b) dsrCABL1/2, (c) dsrCABL1, (d) dsrCABL2, (e) dsrU, (f) dsrT, (g) $d s r M$, (h) complemented $d s r M$ mutant. Incubation times are indicated below the graphs. Growth and metabolic transformation of sulfur compounds had ceased at the end of the experiment. The initial protein content of the cultures was $\sim 100 \mu \mathrm{g} \mathrm{ml}^{-1}$. Sulfide (black bars), sulfur (dark-grey bars), thiosulfate (lightgrey bars) and sulfate (white bars) concentrations were measured. The sulfur recovery (of all sulfur compounds) at the end of the experiment expressed as a percentage of the initial sulfur concentration is shown in the upperright corner. The mean and SD of replicate cultures $(n \geqslant 3)$ are shown. The presence of elemental sulfur at time 0 in $d s r$ mutants is due to carry-over from the inoculum.
Sulfur globules purified from cultures of $d s r$ mutants served as sole sulfur source for other C. tepidum cells. When wild-type cells $\left(30 \mu \mathrm{g}\right.$ protein $\left.\mathrm{ml}^{-1}\right)$ were supplemented with sulfur globules $(\sim 3 \mathrm{mM})$, the sulfur globules were readily oxidized completely to sulfate within $24 \mathrm{~h}$. This suggests that the formation and structure of the sulfur globules produced by the wildtype and the $d s r$ mutants are similar. It also shows that 
sulfur globules produced by one cell are freely available to any other cell.

\section{Sulfide and thiosulfate oxidation rates}

Oxidation rates were measured on whole cells of the wildtype, three $d s r$ mutants $(d s r M, d s r T$ and dsrCABL1/2) and three other mutants lacking genes involved in sulfide oxidation ( $s q r D$, sqrF, sqrD sqrF) (Table 3). Double knockout of the SQR homologues $s q r D$ and $s q r F$ and single knockout of $s q r D$ resulted in a reduced sulfide oxidation rate of about $50 \%$ of that of the wild-type. The single mutant of $s q r F$ did not show a statistically significant variation from the wild-type ( $t$ test, $P<0.05)$. The results show that $s q r D$ is responsible for most $\mathrm{SQR}$ activity in the cells under the conditions tested, in agreement with results obtained with membrane fractions (Chan et al., 2009). The thiosulfate oxidation rate was unaffected in all sqr mutants.

Interestingly, all $d s r$ mutants oxidized sulfide and thiosulfate about twice as fast as the wild-type. In these experiments the light intensity was close to saturation (as in all other experiments reported in this work), and the BChl $c$ to protein ratio was $0.055 \pm 0.010, w / w$, throughout the duration of the experiments and for all strains, which excludes the pigment composition from being responsible for the different oxidation rates. The $d s r$ mutants are not able to obtain as many reducing equivalents per unit of consumed substrate (sulfide or thiosulfate) as the wild-type. Thus, the increased substrate consumption rates presumably allow the $d s r$ mutants to obtain reducing equivalents at a rate similar to that of the wild-type.

Table 3. Sulfide and thiosulfate oxidation rates in C. tepidum wild-type and mutant strains

The measurements were performed on suspensions of whole cells (100-200 $\mu \mathrm{g}$ protein $\mathrm{ml}^{-1}$ ) in CL3 medium with $2 \mathrm{mM}$ sulfide or $2 \mathrm{mM}$ thiosulfate for about $2 \mathrm{~h}$. The mean $\pm \mathrm{SD}$ are shown $(n=4$ for sulfide oxidation measurements in wild-type and all sqr mutants; $n=2$ for all other measurements).

\begin{tabular}{|lcc|}
\hline \multirow{2}{*}{ Strain } & \multicolumn{2}{c|}{ Oxidation rate $\left[\boldsymbol{\mu} \mathbf{m o l ~ h}^{-\mathbf{1}}(\mathbf{m g} \text { protein })^{-\mathbf{1}}\right]$} \\
\cline { 2 - 3 } & Sulfide & Thiosulfate \\
\hline Wild-type & $12.0 \pm 2.8$ & $9.6 \pm 0.3$ \\
$s q r D$ sqrF & $5.7 \pm 1.3$ & $9.9 \pm 2.8$ \\
$s q r D$ & $6.7 \pm 1.0$ & $8.5 \pm 0.7$ \\
$s q r F$ & $11.0 \pm 1.5$ & $8.6 \pm 2.9$ \\
$d s r M$ & $17.9 \pm 2.1$ & $25.2 \pm 3.1$ \\
$d s r T$ & $17.2 \pm 1.8$ & $21.9 \pm 0.8$ \\
dsrCABL1/2 & $20.3 \pm 0.1$ & $25.6 \pm 6.2$ \\
\hline
\end{tabular}

\section{Growth rates and growth yield}

Growth rates were determined by measuring BChl $c$ concentrations in the cultures, when $3 \mathrm{mM}$ sulfide or $3 \mathrm{mM}$ thiosulfate as sole sulfur source was supplied. The ratio of $\mathrm{BChl} c$ to protein was determined to be constant during the experiment. The wild-type grew at a rate of $0.34 \pm 0.02 \mathrm{~h}^{-1} \quad(n=2)$ when sulfide was supplied. This agrees with the published doubling time of $C$. tepidum of $2 \mathrm{~h}$ (Wahlund et al., 1991). The dsrCABL1/2 and sqrD sqrF mutants displayed growth rates of about $70 \%(n=2)$ and $82 \%(n=2)$ of that of the wild-type, respectively, when grown on sulfide. A similar difference in the growth rates of the wild-type $\left(0.38 \pm 0.01 \mathrm{~h}^{-1}, n=2\right)$ and dsrCABL1/2 $\left(0.30 \pm 0.02 \mathrm{~h}^{-1}, n=2\right)$ was observed when thiosulfate was the sulfur source supplied.

Although the growth rates of the wild-type and dsrCABL1/ 2 mutants showed little variation, the growth yields were significantly different. To determine the growth yields, cells were inoculated in CL3 medium with a limiting amount of thiosulfate $(3.5 \mathrm{mM})$. The increase in cellular protein was determined when the culture had consumed all of this thiosulfate and ceased to grow. The wild-type produced $37 \pm 6 \mathrm{~g}$ protein (mol thiosulfate) ${ }^{-1}$ (two biological replicates), which was twice as much as the dsrCABL1/2 mutant, $18 \pm 0 \mathrm{~g}$ protein (mol thiosulfate) ${ }^{-1}$ (two biological replicates). This observation supports the idea that the $d s r$ mutant obtains a growth rate similar to that of the wild-type by increasing the oxidation rate of its substrates, but reaches a much lower growth yield due to the incomplete oxidation of thiosulfate. The sqrD sqrF mutant, due to its reduced sulfide oxidation rate (Table 3 ), has less reducing equivalents available for growth, so a reduced growth rate is expected. The growth yield of the sqrD sqrF mutant grown on sulfide at low concentrations has been reported to be similar to that of the wild-type (Chan et al., 2009), in agreement with the observation that this mutant oxidizes sulfide completely to sulfate.

\section{DISCUSSION}

\section{Function and genetic makeup of the DSR system in GSB}

The phenotype of the $d s r$ mutants showed that the DSR system in C. tepidum is essential for the oxidation of sulfur globules. The same observation has been made in studies of $d s r$ mutants of A. vinosum (Dahl et al., 2005). All sequenced GSB contain the same $d s r$ genes ( $d s r N C A B L U E F H T M K J O-$ $P V W$ ), suggesting that the DSR system functions in the same manner in all GSB. The only exception is Chlorobaculum parvum, which lacks $d s r E F H$ (http://www.ncbi.nlm.nih.gov/ nuccore/NC_011027) and it is not obvious what, if anything, substitutes for the function of DsrEFH in this strain.

C. tepidum has two dsrCABL clusters (CT0851-CT0854 and CT2250-CT2247), which are $99.4 \%$ identical at the 
nucleotide sequence level, although the upstream regions containing putative promoters are different (Fig. 2) (Eisen et al., 2002). The frameshift mutation detected in $d s r B 2$ (Eisen et al., 2002) has been restored in our wild-type strain such that the sequences of $d s r B 1$ and $d s r B 2$ are identical. It is possible that the frameshift restoration and/or $d s r C A B L$ duplication is selected for by an increased content of the DsrCABL enzymes, which may be rate-limiting for growth under sulfur globule-oxidizing conditions.

\section{Thiosulfate formation}

Transient formation of thiosulfate during sulfide oxidation has been observed in certain GSB and PSB (Brune, 1989; Chan et al., 2008b; Steinmetz \& Fischer, 1982; Steudel et al., 1990; Trüper et al., 1988), although the mechanism is not known. Thiosulfate oxidation in C. tepidum is performed by the SOX system (Azai et al., 2009; Ogawa et al., 2008), but is inhibited in the presence of sulfide (Chan et al., 2008b). In our C. tepidum wild-type cultures, thiosulfate accumulated under sulfide-oxidizing conditions and was subsequently consumed when sulfide was depleted (Fig. $3 \mathrm{~b})$. This formation of thiosulfate was not observed in the $d s r$ mutants (Fig. 3d and Supplementary Fig. S1b), suggesting that the DSR system is involved in thiosulfate formation. We propose that a fraction of the reduced sulfur is oxidized by the DSR system to sulfite prior to sulfide depletion, which is then further converted to thiosulfate by an abiotic reaction. Several abiotic mechanisms for thiosulfate formation from sulfite have been reported. Sulfite can react with sulfide, forming elemental sulfur as an intermediate, which then subsequently reacts with sulfite to form thiosulfate and water (Heunisch, 1977). A second possible abiotic reaction forming thiosulfate is a sulfite molecule attacking an oligosulfide chain according to the following reaction scheme (Roy \& Trudinger, 1970):

$\mathrm{S}_{n}^{2-}+\mathrm{SO}_{3}^{2-} \rightarrow \mathrm{S}_{n-1}^{2-}+\mathrm{S}_{2} \mathrm{O}_{3}^{2-}$

Sulfite could accumulate in the cells if sulfite oxidation is inhibited or is not as rapid as the sulfite formation at high sulfide concentrations. Subsequent formation of thiosulfate from sulfite could take place either in the cytoplasm or in the periplasm, depending on where the sulfite accumulates. Excretion of sulfite or thiosulfate from the cytoplasm could be meditated by the putative sulfate transporter in GSB (CT0714; Eisen et al., 2002; Fig. 1), since some sulfate transporters allow transfer of related anions such as sulfite and thiosulfate (Kredich, 1996).

\section{Sulfide oxidation}

We conclude that sulfide is oxidized by several enzymes in C. tepidum. Table 3 shows that a mutant lacking the two SQR homologues, SqrD and SqrF, has sulfide oxidation rates about $50 \%$ of those of the wild-type. Chan and coworkers could not detect any sulfide-dependent quinone reduction activity in membrane preparations from an $s q r D$ sqrF mutant of C. tepidum (Chan et al., 2009). Thus, sulfide oxidation activity in C. tepidum cells other than that due to SQR enzymes could be due to periplasmic enzymes or to membrane-bound enzymes that either do not retain their activity when membranes are prepared or use an electron acceptor different from the ones tested by Chan et al. (2009). The sqrD sqrF double mutant transiently accumulates sulfur globules. Thus, at least one of the non-SQR sulfide-oxidizing enzymes must be producing precursors of sulfur globule formation, possibly oligosulfides. The observation that the sqrD sqrF mutant was not able to increase the sulfide oxidation rate, as observed in the $d s r$ mutants (Table 3), even though sulfide oxidation appeared to be limiting for growth, indicates that it is the SQRcatalysed sulfide oxidation which is enhanced in the $d s r$ mutants.

\section{Ecophysiological significance of the DSR system}

Chloroherpeton is an early branching GSB that lacks $d s r$ genes (Frigaard \& Bryant, 2008). Sulfide is required for growth of Chloroherpeton and sulfur globules accumulate outside the cells upon sulfide oxidation. These sulfur globules 'only very slowly disappear' in culture (Gibson et al., 1984), although it is not clear what the degradation product is. The DSR system that occurs in other GSB is an evolutionary chimera, since the membrane-bound proteins DsrTMKJOP are related to those in sulfate-reducing chemotrophs, and the soluble proteins DsrABCLEFH are related to those in PSB (Sander et al., 2006). These and additional phylogenetic analyses suggest that the DSR system may have been acquired by the Chlorobi lineage after the divergence of Chloroherpeton (Frigaard \& Bryant, 2008). If so, the Chlorobi lineage may have been unable to completely oxidize sulfide to sulfate prior to the horizontal transfer of $d s r$ genes. However, the absence of a DSR system is not necessarily a significant disadvantage, because the growth rates of the $d s r$ mutants observed in the present work suggest that GSB are able to sustain efficient growth by oxidizing sulfide exclusively to elemental sulfur provided that sulfide is not limiting. In natural environments, sulfur-reducing prokaryotes could maintain a nonlimiting supply of sulfide. Examples of such stable symbiotic associations of GSB and a sulfur reducer, Desulfuromonas acetoxidans, have been described (Biebl \& Pfennig, 1978). Chloroherpeton also grows very well in coculture with D. acetoxidans (Gibson et al., 1984). In these co-cultures, complete oxidation of sulfide to sulfate is unfavourable to the GSB partner because the sulfurreducing partner cannot reduce sulfate. In addition, the availability of sulfur globules may be advantageous to GSB, because they can use the sulfur globules (and not sulfate) as electron acceptor in the dark, and thereby presumably increase the energy gained from fermentation of intracellular storage polyglucose (Brune, 1989). The mechanism that causes release of elemental sulfur in GSB, as opposed to the intracellular sulfur globules in PSB, could thus be 
illustrating a lifestyle in which complete oxidation is not beneficial. However, once GSB grow in environments with very low concentrations of sulfide, such as at the edge of the sulfide gradient in stratified water columns or sediments (Overmann, 2008), complete oxidation of sulfur and a wider substrate range (e.g. thiosulfate) could become a competitive advantage. In fact, studies with continuous cultures of GSB show that under sulfide limitation, the organisms will produce both sulfur globules and sulfate (Van Gemerden, 1986).

\section{ACKNOWLEDGEMENTS}

This work was supported by a grant from the Danish Natural Science Research Council to N.-U.F. (21-04-0463). C. H. was supported by a scholarship from the Studienstiftung des Deutschen Volkes.

\section{REFERENCES}

Azai, C., Tsukatani, Y., Harada, J. \& Oh-oka, H. (2009). Sulfur oxidation in mutants of the photosynthetic green sulfur bacterium Chlorobium tepidum devoid of cytochrome c-554 and SoxB. Photosynth Res 100, 57-65.

Biebl, H. \& Pfennig, N. (1978). Growth yields of green sulfur bacteria in mixed cultures with sulfur and sulfate reducing bacteria. Arch Microbiol 117, 9-16.

Brune, D. C. (1989). Sulfur oxidation by phototrophic bacteria. Biochim Biophys Acta 975, 189-221.

Chan, L.-K., Morgan-Kiss, R. M. \& Hanson, T. E. (2008a). Genetic and proteomic studies of sulfur oxidation in Chlorobium tepidum (syn. Chlorobaculum tepidum). In Sulfur Metabolism in Phototrophic Organisms, pp. 357-373. Edited by R. Hell, C. Dahl, D. B. Knaff \& T. Leustek. Dordrecht: Springer.

Chan, L.-K., Weber, T. S., Morgan-Kiss, R. M. \& Hanson, T. E. (2008b). A genomic region required for phototrophic thiosulfate oxidation in the green sulfur bacterium Chlorobium tepidum (syn. Chlorobaculum tepidum). Microbiology 154, 818-829.

Chan, L.-K., Morgan-Kiss, R. M. \& Hanson, T. E. (2009). Functional analysis of three sulfide:quinone oxidoreductase homologs in Chlorobaculum tepidum. J Bacteriol 191, 1026-1034.

Cline, J. D. (1969). Spectrophotometric determination of hydrogen sulfide in natural waters. Limnol Oceanogr 14, 454-458.

Dahl, C., Engels, S., Pott-Sperling, A. S., Schulte, A., Sander, J., Lübbe, Y., Deuster, O. \& Brune, D. C. (2005). Novel genes of the $d s r$ gene cluster and evidence for close interaction of Dsr proteins during sulfur oxidation in the phototrophic sulfur bacterium Allochromatium vinosum. J Bacteriol 187, 1392-1404.

Eisen, J. A., Nelson, K. E., Paulsen, I. T., Heidelberg, J. F., Wu, M., Dodson, R. J., Deboy, R., Gwinn, M. L., Nelson, W. C. \& other authors (2002). The complete genome sequence of Chlorobium tepidum TLS, a photosynthetic, anaerobic, green-sulfur bacterium. Proc Natl Acad Sci U S A 99, 9509-9514.

Frigaard, N.-U. \& Bryant, D. A. (2001). Chromosomal gene inactivation in the green sulfur bacterium Chlorobium tepidum by natural transformation. Appl Environ Microbiol 67, 2538-2544.

Frigaard, N.-U. \& Bryant, D. A. (2008). Genomic insights into the sulfur metabolism of phototrophic green sulfur bacteria. In Sulfur Metabolism in Phototrophic Organisms, pp. 337-355. Edited by R. Hell, C. Dahl, D. B. Knaff \& T. Leustek. Dordrecht: Springer.
Frigaard, N.-U. \& Dahl, C. (2009). Sulfur metabolism in phototrophic sulfur bacteria. In Advances in Microbial Physiology, pp. 103-200. Edited by R. K. Poole. London: Academic Press.

Frigaard, N.-U., Chew, A. G. M., Li, H., Maresca, J. A. \& Bryant, D. A. (2003). Chlorobium tepidum: insights into the structure, physiology, and metabolism of a green sulfur bacterium derived from the complete genome sequence. Photosynth Res 78, 93-117.

Frigaard, N.-U., Sakuragi, Y. \& Bryant, D. A. (2004). Gene inactivation in the cyanobacterium Synechococcus sp. PCC 7002 and the green sulfur bacterium Chlorobium tepidum using in vitro-made DNA constructs and natural transformation. In Methods in Molecular Biology, pp. 325340. Edited by R. Carpentier. Totowa, NJ: Humana Press.

Gibson, J., Pfennig, N. \& Waterbury, J. B. (1984). Chloroherpeton thalassium gen. nov. et spec. nov., a non-filamentous, flexing and gliding green sulfur bacterium. Arch Microbiol 138, 96-101.

Grimm, F., Cort, J. R. \& Dahl, C. (2010). DsrR, a novel IscA-like protein lacking iron- and Fe-S-binding functions, involved in the regulation of sulfur oxidation in Allochromatium vinosum. J Bacteriol 192, 1652-1661.

Heunisch, G. W. (1977). Stoichiometry of the reaction of sulfites with hydrogen sulfide ion. Inorg Chem 16, 1411-1413.

Imhoff, J. F. (2008). Systematics of anoxygenic phototrophic bacteria. In Sulfur Metabolism in Phototrophic Organisms, pp. 269-287. Edited by R. Hell, C. Dahl, D. Knaff \& T. Leustek. Dordrecht: Springer.

Jacobsen, J. H., Rosgaard, L., Sakuragi, Y. \& Frigaard, N.-U. (2011). One-step plasmid construction for generation of knock-out mutants in cyanobacteria: studies of glycogen metabolism in Synechococcus sp. PCC 7002. Photosynth Res 107, 215-221.

Klein, M., Friedrich, M., Roger, A. J., Hugenholtz, P., Fishbain, S., Abicht, H., Blackall, L. L., Stahl, D. A. \& Wagner, M. (2001). Multiple lateral transfers of dissimilatory sulfite reductase genes between major lineages of sulfate-reducing prokaryotes. J Bacteriol 183, 6028-6035.

Kredich, N. M. (1996). Biosynthesis of cysteine. In Escherichia coli and Salmonella, Cellular and Molecular Biology, pp. 514-527. Edited by F. C. Neidhardt. Washington, DC: American Society for Microbiology.

Lübbe, Y. J., Youn, H. S., Timkovich, R. \& Dahl, C. (2006). Siro(haem)amide in Allochromatium vinosum and relevance of DsrL and DsrN, a homolog of cobyrinic acid $a, c$-diamide synthase, for sulphur oxidation. FEMS Microbiol Lett 261, 194-202.

Maresca, J. A., Romberger, S. P. \& Bryant, D. A. (2008). Isorenieratene biosynthesis in green sulfur bacteria requires the cooperative actions of two carotenoid cyclases. J Bacteriol 190, 6384-6391.

Meyer, B., Imhoff, J. F. \& Kuever, J. (2007). Molecular analysis of the distribution and phylogeny of the soxB gene among sulfur-oxidizing bacteria - evolution of the Sox sulfur oxidation enzyme system. Environ Microbiol 9, 2957-2977.

Mussmann, M., Richter, M., Lombardot, T., Meyerdierks, A., Kuever, J., Kube, M., Glöckner, F. O. \& Amann, R. (2005). Clustered genes related to sulfate respiration in uncultured prokaryotes support the theory of their concomitant horizontal transfer. J Bacteriol 187, 7126-7137.

Ogawa, T., Furusawa, T., Nomura, R., Seo, D., Hosoya-Matsuda, N., Sakurai, H. \& Inoue, K. (2008). SoxAX binding protein, a novel component of the thiosulfate-oxidizing multienzyme system in the green sulfur bacterium Chlorobium tepidum. J Bacteriol 190, 6097-6110.

Overmann, J. (2008). Ecology of phototrophic sulfur bacteria. In Sulfur Metabolism in Phototrophic Organisms, pp. 375-396. Edited by R. Hell, C. Dahl, D. B. Knaff \& T. Leustek. Dordrecht: Springer.

Pott, A. S. \& Dahl, C. (1998). Sirohaem sulfite reductase and other proteins encoded by genes at the $d s r$ locus of Chromatium vinosum are involved in the oxidation of intracellular sulfur. Microbiology 144, 1881-1894. 
Prange, A., Chauvistré, R., Modrow, H., Hormes, J., Trüper, H. G. \& Dahl, C. (2002). Quantitative speciation of sulfur in bacterial sulfur globules: X-ray absorption spectroscopy reveals at least three different species of sulfur. Microbiology 148, 267-276.

Roy, A. B. \& Trudinger, P. A. (1970). The Biochemistry of Inorganic Compounds of Sulphur. Cambridge, UK: Cambridge University Press.

Sakurai, H., Ogawa, T., Shiga, M. \& Inoue, K. (2010). Inorganic sulfur oxidizing system in green sulfur bacteria. Photosynth Res 104, 163-176.

Sander, J., Engels-Schwarzlose, S. \& Dahl, C. (2006). Importance of the DsrMKJOP complex for sulfur oxidation in Allochromatium vinosum and phylogenetic analysis of related complexes in other prokaryotes. Arch Microbiol 186, 357-366.

Schübbe, S., Williams, T. J., Xie, G., Kiss, H. E., Brettin, T. S., Martinez, D., Ross, C. A., Schüler, D., Cox, B. L. \& other authors (2009). Complete genome sequence of the chemolithoautotrophic marine magnetotactic coccus strain MC-1. Appl Environ Microbiol 75, $4835-4852$.

Stal, L. J., van Gemerden, H. \& Krumbein, W. E. (1984). The simultaneous assay of chlorophyll and bacteriochlorophyll in natural microbial communities. J Microbiol Methods 2, 295-306.

Stanier, R. Y. \& Smith, J. H. C. (1960). The chlorophylls of green bacteria. Biochim Biophys Acta 41, 478-484.
Steinmetz, M. A. \& Fischer, U. (1982). Cytochromes of the green sulfur bacterium Chlorobium vibrioforme f. thiosulfatophilum. Purification, characterization and sulfur metabolism. Arch Microbiol 131, 19-26.

Steudel, R., Holdt, G., Visscher, P. T. \& Van Gemerden, H. (1990). Search for polythionates in cultures of Chromatium vinosum after sulfide incubation. Arch Microbiol 153, 432-437.

Theissen, U., Hoffmeister, M., Grieshaber, M. \& Martin, W. (2003). Single eubacterial origin of eukaryotic sulfide:quinone oxidoreductase, a mitochondrial enzyme conserved from the early evolution of eukaryotes during anoxic and sulfidic times. Mol Biol Evol 20, 1564-1574.

Trüper, H. G., Lorenz, C., Schedel, M. \& Steinmetz, M. A. (1988). Metabolism of thiosulfate in Chlorobium. In Green Photosynthetic Bacteria, pp. 189-200. Edited by J. Olson, J. G. Ormerod, J. Amesz, E. Stackebrandt \& H. G. Trüper. New York: Plenum Press.

Van Gemerden, H. (1986). Production of elemental sulfur by green and purple sulfur bacteria. Arch Microbiol 146, 52-56.

Wahlund, T. M., Woese, C. R., Castenholz, R. W. \& Madigan, M. T. (1991). A thermophilic green sulfur bacterium from New Zealand hot springs, Chlorobium tepidum sp. nov. Arch Microbiol 156, 81-90.

Edited by: G. Muyzer 